\title{
THEORETICAL AND EXPERIMENTAL EVALUATION OF THERMAL RESISTANCE FOR COMPRESSION BANDAGES
}

\author{
A. R. Aboalasaad ${ }^{1, *}$, B. K. Sirková', T. Mansoor ${ }^{2}$, Z. Skenderi ${ }^{3}$, A. S. Khaliil \\ 1 Department of Technologies and Structures, Technical University of Liberec, Liberec 46117, Czechia \\ 2 Department of Textile Evaluation, Technical University of Liberec, Liberec 46117, Czechia \\ 3 Faculty of Textile Technology, University of Zagreb, Zagreb 10000, Croatia \\ ${ }^{*}$ Corresponding author: E-mail: eabdo6@gmail.com
}

\begin{abstract}
:
The objective of this paper is to report a study on the prediction of the steady-state thermal resistance of woven compression bandage (WCB) by using three different mathematical models. The experimental samples of WCB were $100 \%$ cotton, cotton-polyamide-polyurethane, and viscose-polyurethane. The bandage samples were evaluated at extensions ranging at 10-100\%, with two- and three-layer bandaging techniques. Experimental thermal resistance was measured by thermal foot manikin (TFM) and ALAMBETA testing devices. The obtained results by TFM and ALAMBETA were validated and compared with the theoretical models (Maxwell-Eucken2, Schuhmeister, and Militky), and a reasonable correlation of approximately $78 \%, 92 \%$, and $93 \%$ for ALAMBETA and $75 \%$, 82\%, and 83\% for TFM, respectively, was observed.
\end{abstract}

\section{Keywords:}

Mathematical models for thermal resistance, thermal foot manikin, ALAMBETA, woven bandage properties

\section{Introduction}

\subsection{Overview of thermal resistance testing on thermal manikins}

Thermal manikins are devices by means of which it is possible to simulate heat exchange between humans and the environment $[1,2]$. Human thermal comfort is defined as a condition of mind, which expresses satisfaction with the surrounding environment. High temperatures and humidity provide discomforting sensations and sometimes heat stress, which leads to reduce the body's ability to cool itself. Moreover, this discomfort reduces the productivity of workers and may lead to more serious health problems, especially for aged people [3].

Clothing comfort is an important factor in the stage at which people make their clothing selections [3]. The thermal resistance $\left(R_{c t}\right)$ of fabrics is a primary determinant of body heat loss in cold environments. Generally, high $R_{c t}$ values of clothing are required to maintain the body under thermal equilibrium conditions. In hot environments or at high activity levels, evaporation of sweat becomes an important avenue for body heat loss, and fabrics must allow water vapor to escape in time to maintain the relative humidity between the skin and the first layer of clothing to about $50 \%$ [3-6]. Perspiration is the process of losing body heat due to the evaporation of moisture from the skin to the environment [7]. The warm-cool feeling is another parameter showing thermal comfort. When a human touches a garment that has a temperature that is different than that of the skin, heat exchange occurs between the hand and the fabric, so the warm-cool feeling is the first sensation. Which feeling is better depends on the customer - a cooler feeling is demanded in hot summer, while a warmer feeling is preferred in winter [8].

\subsection{Factors affecting testing of thermal resistance on thermal foot manikin (TFM) and ALAMBETA}

The measurement of clothing insulation with a thermal manikin is a dynamically balanced adjustment process, which initially depends on the central temperature inside the manikin. It means that continuous adjustment of heat flux makes the manikin skin temperature approach a constant temperature gradually under the heat diffusion. These adjustments limit the change in the manikin skin temperature of all parts to a range of $\pm 0.5^{\circ} \mathrm{C}$ around the required temperature. The final state is that the manikin skin temperature is steady and very close to the constant temperature [9].

The main factors affecting testing of $R_{c t}$ are the temperature difference between ambient conditions and skin, yarn structure and material, fabric structure (fibrous assembly), thickness, porosity, areal density, and number of fabric layers which increase the static air [10]. Porosity can be defined as the fraction of void space in the total material volume [11]. It has a vital role in evaluating the thermal performance of any fibrous material. The $R_{c t}$ increases proportionally when the porosity increases by $70-90 \%$ [12]. 


\subsection{Effect of air convection on thermal resistance of multilayer fabrics}

Convection is a process in which heat is transferred by a moving fluid (liquid or gas). For example, air in contact with the body is heated by conduction, and then carried away from the body by convection [13].

Acommon method for removing water from textiles is convective drying. When the fluid starts at a constant temperature and the surface temperature is suddenly increased above that of the fluid, there will be convective heat transfer from the surface to the fluid as a result of the temperature difference $(\Delta T)$. The rate of heat transfer $(Q)$ due to convection can be calculated by Newton's law of cooling, as follows [14]:

$$
\mathrm{Q}=\alpha \mathrm{A} \Delta \mathrm{T}
$$

where $A$ is the heat transfer surface area and $\alpha$ is the coefficient of heat transfer by convection.

When people wear multilayer clothing ensembles in cold weather conditions or in hot environments, air spaces are present between the skin and the inner layer or between two adjacent layers. The $R_{c t}$ of multilayer fabrics with air spaces increases generally as the thickness of the air spaces increases up to a critical point. When the thickness of the air space increases further above this point, the rate of increase in $R_{c t}$ is found to be slow owing to disturbance in the convection and turbulence. This critical thickness was observed to be variable in different studies. Thus, including air spaces that are close to real life is an effective way to enhance the $R_{c t}$ of multilayer fabrics [15].

\subsection{Thermal resistance models and their applications}

The thermal resistance of fabrics can be calculated by means of experimental, analytical, and numerical methods $[16,17]$. There are many models to be found within the textile engineering and heat transfer fields for the thermal resistance prediction. The preference of selection depends on the requisite precision and nature of the solution. Conductive heat transfer is the simplest way to illustrate mathematically and is often the key way of heat transfer [18].

Numerical solutions deal with materials of irregular shapes and properties, different types of heat transfer, and boundary conditions. Numerical methods also have the capability to achieve the maximum precision [19]. There are many commercially available softwares that allow users to solve their problems through numerical solutions. However, these methods are inherently more difficult and complicated, and in some conditions, simple methods prove to be more accurate at much less effort [20]. Thermal resistance is also predicted by using artificial neural networks and statistical models. Some researchers have predicted the thermal resistance of fabrics using mathematical approaches.

Schuhmeister suggested a relationship for the thermal conductivity prediction of fabrics by assuming one-third of fibers to be parallel and two-third in series with a homogeneous distribution in all directions [21]. Later, many researchers used Schuhmeister's model by assuming different ratios of series and parallel components [22-24]. Presently, Mansoor et al. $[25,26]$ have modified Schuhmeister and Militky models by combining the water and fiber filling coefficients for the prediction of thermal resistance of wet socks.

Das et al. [27] calculated the heat transfer through the fabric assemblies with the electric resistance and Fricke's law analogy by assuming them as cuboids packed with randomly oriented infinite fibers. Wie et al. [28] suggested a model for fabric thermal resistance prediction by assuming that heat passes through the fabric as a combination of fiber and air in series plus the air in parallel.

Most studies on $R_{c t}$ of textiles were performed either on knitted fabrics or nonwoven, with only a few on woven fabrics [29-33]. Hence it was necessary to evaluate and distinguish the $R_{c t}$ of woven compression bandage (WCB), dealing with different yarn materials, fabric structures, and number of bandage layers as a function of the applied extension and packing density during testing. Then the experimental results of $R_{c t}$ were validated using the following three theoretical models.

\subsubsection{Maxwell-Eucken2 model}

The Maxwell-Eucken (ME) model (Eq. (2)) can be used to describe the effective thermal conductivity of a twocomponent material with simple physical structures. In Eq. (2), $\lambda_{\mathrm{a}}, \lambda_{\text {polymer }}, \mathrm{F}_{\mathrm{a}}$, and $\mathrm{F}_{\text {polymer }}$ are the thermal conductivities and volume fractions, respectively, and the subscripts represent the two components of the system. The effective thermal conductivity of the two-component material is $\lambda_{f a b}$ [34]. An emulsion is a dispersion of one liquid in another immiscible liquid. The phase that is present in the form of droplets is the dispersed phase and the phase in which the droplets are suspended is called the continuous phase. A number of effective thermal conductivity models require the naming of a continuous and a dispersed phase. In materials with exterior porosity, individual solid particles are surrounded by a gaseous matrix, and hence the gaseous component forms the continuous phase while the solid component forms the dispersed phase. For external porosity, $\lambda_{\mathrm{a}}$ and $\lambda_{\text {polymer }}$ are considered as the continuous and dispersed phases, respectively [35, 36].

$$
\lambda_{\text {fab }}=\frac{\lambda_{a} F_{a}+\lambda_{\text {polymer }} F_{\text {polymer }} \frac{3 \lambda_{a}}{2 \lambda_{a}+\lambda_{\text {polymer }}}}{F_{a}+F_{\text {polymer }} \frac{3 \lambda_{a}}{2 \lambda_{a}+\lambda_{\text {polymer }}}}
$$

$F_{\text {polymer }}$ and $\lambda_{\text {polymer }}$ are calculated based on Eqs (7) and (8).

\subsubsection{Schuhmeister's model}

Schuhmeister summarized the relationship between the thermal conductivity and structural parameters of a fabric using Eq. (3): 


$$
\begin{aligned}
& \lambda_{\text {fab }}=0.67 \times \lambda_{s}+0.33 \times \lambda_{p} \\
& \lambda_{s}=\frac{\lambda_{\text {polymer }} \times \lambda_{a}}{\lambda_{\text {polymer }} F_{a}+\lambda_{a} F_{\text {polymer }}} \\
& \lambda_{p}=F_{\text {polymer }} \lambda_{\text {polymer }}+F_{a} \lambda_{a}
\end{aligned}
$$

where $\lambda_{f a b}$ is the thermal conductivity of a fabric, $\lambda_{\text {polymer }}$ is the conductivity of fibers, $\lambda_{a}$ is the conductivity of air, $F_{\text {polymer }}$ is the filling coefficient of the solid fiber, and $F_{a}$ is the filling coefficient of air in the insulation [37].

\subsubsection{Militky's model}

Militky summarized the relationship between the thermal conductivity and structural parameters of a fabric usina empirical Eq. (6) and used the same steps for calculating $\lambda_{s}$ and $\lambda_{p}$ using Eqs (4) and (5), respectively [23, 38], as follows:

$$
\lambda_{\text {fab }}=\left(\frac{\lambda_{s}+\lambda_{p}}{2}\right)
$$

\subsection{Average thermal conductivity and filling coefficient calculations}

It is assumed that fabric density changes with wetting, which causes a change in the filling coefficient, porosity, and thermal conductivity of the fabrics. Based on these assumptions the following three equations were developed that will be used to find the fabric density, filling coefficient, and thermal conductivity for different moisture levels. The average thermal conductivity for different fibers (within socks) at different moisture levels are calculated based on Eq. (7) as follows:

Average thermal conductivity $\left(\lambda_{\text {polymer }}\right)=\left(\frac{F_{f b 1} \cdot \lambda_{f i b 1}+F_{f i b 2} \cdot \lambda_{f b b 2}+F_{f i b 3} \cdot \lambda_{f b b 3}}{F_{f b 1}+F_{f b b 2}+F_{f b b 3}}\right)$

$F_{\text {fib1 }}=$ First fiber filling coefficient

$F_{\text {fib2 }}=$ Second fiber filling coefficient

$F_{\text {fib3 }}=$ Third fiber filling coefficient

$\lambda_{\text {fib1 }}=$ First fiber thermal conductivity

$\lambda_{\text {fib2 }}=$ Second fiber thermal conductivity

$\lambda_{\text {fib3 }}=$ Third fiber thermal conductivity

Filling coefficients for fiber and air are calculated as listed in Table 1, according to the following steps.

Air filling coefficient $\left(F_{a}\right)$ is calculated as follows:

Air filling coefficient $\left(F_{a}\right)=1-F_{f i b}$
The outputs of Eqs (7) and (8) are used as input for all the above models. Thermal conductivity of water and air is taken as 0.6 and $0.026 \mathrm{~W} / \mathrm{m} / \mathrm{K}$ while density of water is $1,000 \mathrm{Kg} / \mathrm{m}^{3}$. The values of the different input parameters used in this study are listed in Table 2 [39].

\section{Experimental work}

\subsection{Materials}

Experimental samples are $100 \%$ bleached cotton (BL$\mathrm{CO})$, cotton-polyamide-polyurethane (CO-PA-PU), and viscose-polyurethane (VI-PU) bandages. All $R_{c t}$ tests and measurements of the areal density of samples $\left(\mathrm{g} / \mathrm{m}^{2}\right)$ and total thickness are performed on the extended state as illustrated in Table 3 .

\subsection{Testing procedure}

\subsubsection{Adjusting the testing procedure of Rct on TFM and ALAMBETA}

Thermal manikins are designed to simulate the human body's heat exchange and its interaction with the surrounding environment. There are two types of testing on thermal manikin, practically called "nude and clothed Manikin" [2]. Experimental samples consist of three types of WCBs, which as porous materials should provide thermal comfort to

Table 1. Filling coefficients calculation

\begin{tabular}{|c|c|}
\hline Measurement & $\boldsymbol{F}_{\text {fib }}=$ Fiber filling coefficient \\
\hline Content & $\%$ \\
\hline Weight & $\mathrm{G}$ \\
\hline Area & $\mathrm{m}^{2}$ \\
\hline Areal density & $\mathrm{g} / \mathrm{m}$ \\
\hline Volumetric density & $\frac{\text { Fabric areal density }}{\text { Fabric thickness }}\left[\mathrm{Kg} / \mathrm{m}^{3}\right]$ \\
\hline Filling coefficient & $\frac{\text { Volumetric density }}{\text { Fiber density }}$ \\
\hline
\end{tabular}

Table 2. Different fiber properties

\begin{tabular}{|c|c|c|}
\hline Fiber name & Density $\left(\mathbf{K g} / \mathbf{m}^{3}\right)$ & $\begin{array}{c}\text { Thermal } \\
\text { conductivity } \\
\text { (W/m/K) }\end{array}$ \\
\hline Cotton & 1,540 & 0.5 \\
\hline Viscose & 1,530 & 0.5 \\
\hline Polyester & 1,360 & 0.4 \\
\hline Nylon 66 & 1,140 & 0.3 \\
\hline Polypropylene & 900 & 0.2 \\
\hline Wool & 1,310 & 0.5 \\
\hline Acrylic & 1,150 & 0.3 \\
\hline
\end{tabular}


enable air permeability, heat transfer, and liquid perspiration out of the human body. Mercerized cotton socks were used to cover TFM as underwear to measure $R_{c t 0}$ for all measured samples to ensure more stabilization and steady conditions before measuring $R_{c t}$. The testing method in this case is called "clothed Manikin." The three types of WCBs were wrapped on TFM at $50 \%$ extension using both $50 \%$ and $66 \%$ overlap to achieve two- and three-layer bandaging, respectively (see Figure 1). Thermal resistance was evaluated for all samples at the standard ambient conditions ( $\mathrm{T}: 20 \pm 2^{\circ} \mathrm{C}, \mathrm{RH}: 65 \pm 5 \%$ ) using TFM at air convection speed $0-0.25 \mathrm{~m} / \mathrm{s}$ for all types of WCBs, as shown in Figures 1 and 2 [40]. Then the $R_{c t}$ results by TFM and ALAMBETA were validated using the three theoretical models, such as ME-2, Schuhmeister, and Militky.

However, the same tests were confirmed on ALAMBETA at the same extension and number of layers using special tensioning frame, as shown in Figure 3, but using the free air convection system [41].

2.2.2. Calculating and measuring $R_{c t}$ on TFM and ALAMBETA respectively

The stabilization process of the TFM could be achieved after $20 \mathrm{~min}$ - at least - then the final testing step takes place [10].
Finally, $R_{c t}$ values can be measured using the measured $R_{c t 0}$ as a reference value, as illustrated in Figure 4, and it can be calculated using Eq. (9) as follows:

$$
R_{c t}=\frac{A \cdot\left(T_{s}-T_{a}\right)}{H}-R_{c t 0}
$$

where $R_{c t}$ is the dry resistance of sample only $\left(\mathrm{m}^{2} .{ }^{\circ} \mathrm{C} / \mathrm{W}\right)$, or $\left(\mathrm{m}^{2} .{ }^{\circ} \mathrm{C} . \mathrm{W}^{-1}\right) T_{s}$ is the hot plate surface temperature $\left({ }^{\circ} \mathrm{C}\right), T_{a}$ is ambient temperature $\left({ }^{\circ} \mathrm{C}\right), H / A$ is the zone heat flux $\left(\mathrm{W} / \mathrm{m}^{2}\right)$, and $R_{c t 0}$ is the clothed TFM dry resistance $\left(\mathrm{m}^{2} /{ }^{\circ} \mathrm{C} / \mathrm{W}\right)$.

\section{Results and discussion}

\subsection{Thermal resistance measured by TFM compared with ALAMBETA}

For comparison, all bandage types were wrapped on TFM and ALAMBETA at the same extension level ranging from $10 \%$ to $100 \%$ using both two and three layers of bandages [10]. Figure 5 illustrates that $R_{c t}$ values slightly improve when the applied extension increases on ALAMBETA; on the contrary, it is significantly decreasing for TFM. The main effective factors on ALAMBETA are the bandage volumetric porosity and the

\begin{tabular}{|l|l|l|l|l|l|l|}
\hline $\begin{array}{l}\text { Bandage } \\
\text { code }\end{array}$ & BL-CO-2 & BL-CO-3 & $\begin{array}{l}\text { CO-PA- } \\
\text { PU-2 }\end{array}$ & $\begin{array}{l}\text { CO-PA- } \\
\text { PU-3 }\end{array}$ & VI-PU-2 & VI-PU-3 \\
\hline $\begin{array}{l}\text { Adjusting } \\
\text { bandage } \\
\text { extension and } \\
\text { number of } \\
\text { layers on TFM }\end{array}$ & & & & & & \\
\hline
\end{tabular}

Figure 1. Adjusting the bandage extensions and number of layers on the thermal foot manikin (TFM).

Table 3. Specifications of woven bandage samples on thermal foot manikin

\begin{tabular}{|c|c|c|c|c|}
\hline $\begin{array}{l}\text { Sample } \\
\text { code }\end{array}$ & Fiber composition & Sample type & Weight $\left(g / \mathrm{m}^{2}\right)$ & Thickness (mm) \\
\hline BL-CO-2 & Bleached cotton $100 \%$ & $\begin{array}{l}100 \% \text { cotton, two layers, } 50 \% \\
\text { extension, } 50 \% \text { overlap }\end{array}$ & $\begin{array}{c}\text { Two layers = } \\
212.3\end{array}$ & $\begin{array}{l}\text { One layer }=0.76 \\
\text { Two layers }=1.39\end{array}$ \\
\hline $\begin{array}{l}\text { CO-PA- } \\
\text { PU-2 }\end{array}$ & $\begin{array}{c}\text { Cotton } 78 \% \text {, polyamide } 16 \% \text {, } \\
\text { polyurethane } 6 \%\end{array}$ & $\begin{array}{l}\text { CO-PA-PU, two layers, } 50 \% \\
\text { extension, } 50 \% \text { overlap }\end{array}$ & $\begin{array}{c}\text { Two layers }= \\
238.1\end{array}$ & $\begin{array}{l}\text { One layer }=0.84 \\
\text { Two layers }=1.53\end{array}$ \\
\hline VI-PU-2 & Viscose $94 \%$, polyurethane $6 \%$ & $\begin{array}{c}\text { VI-PU, two layers, } 50 \% \text { extension, } \\
50 \% \text { overlap }\end{array}$ & $\begin{array}{c}\text { Two layers }= \\
220.7\end{array}$ & $\begin{array}{l}\text { One layer }=0.79 \\
\text { Two layers }=1.43\end{array}$ \\
\hline BL-CO-3 & Bleached cotton $100 \%$ & $\begin{array}{l}100 \% \text { cotton, three layers, } 50 \% \\
\text { extension, } 66 \% \text { overlap }\end{array}$ & $\begin{array}{c}\text { Three layers }= \\
317.5\end{array}$ & $\begin{array}{c}\text { One layer }=0.76 \\
\text { Three layers }=2.01\end{array}$ \\
\hline $\begin{array}{l}\text { CO-PA- } \\
\text { PU-3 }\end{array}$ & $\begin{array}{c}\text { Cotton } 78 \% \text {, polyamide } 16 \%, \\
\text { polyurethane } 6 \%\end{array}$ & $\begin{array}{l}\text { CO-PA-PU, three layers, } 50 \% \\
\text { extension, } 66 \% \text { overlap }\end{array}$ & 356.3 & $\begin{array}{c}\text { One layer }=0.84 \\
\text { Three layers }=2.17\end{array}$ \\
\hline VI-PU-3 & Viscose $94 \%$, polyurethane $6 \%$ & $\begin{array}{c}\text { VI-PU, three layers, } 50 \% \text { extension, } \\
66 \% \text { overlap }\end{array}$ & 329.4 & $\begin{array}{l}\text { One layer }=0.79 \\
\text { Three layers }=2.05\end{array}$ \\
\hline
\end{tabular}




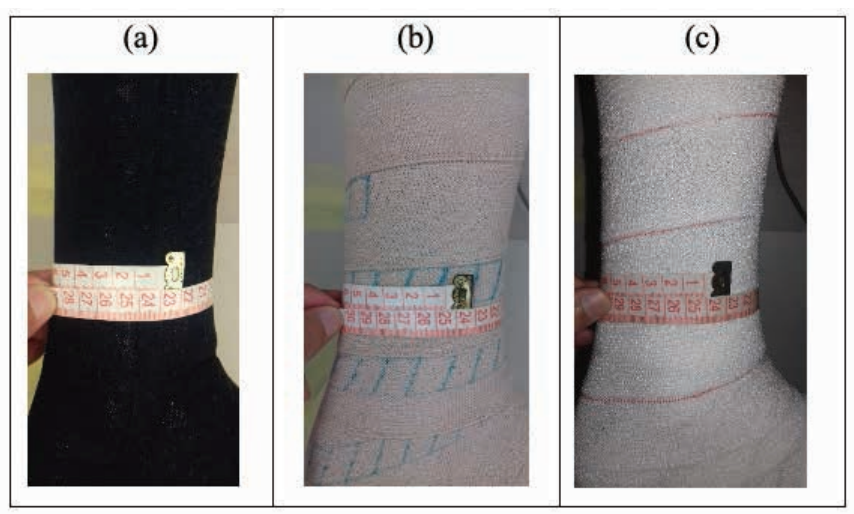

Figure 2. Measuring the total bandage thickness on thermal foot manikin. (A) clothed TFM with socks without bandage, (B) TFM with socks and CO-PA-PU-2 bandage, and (C) TFM with socks and VI-PU-2 bandage.

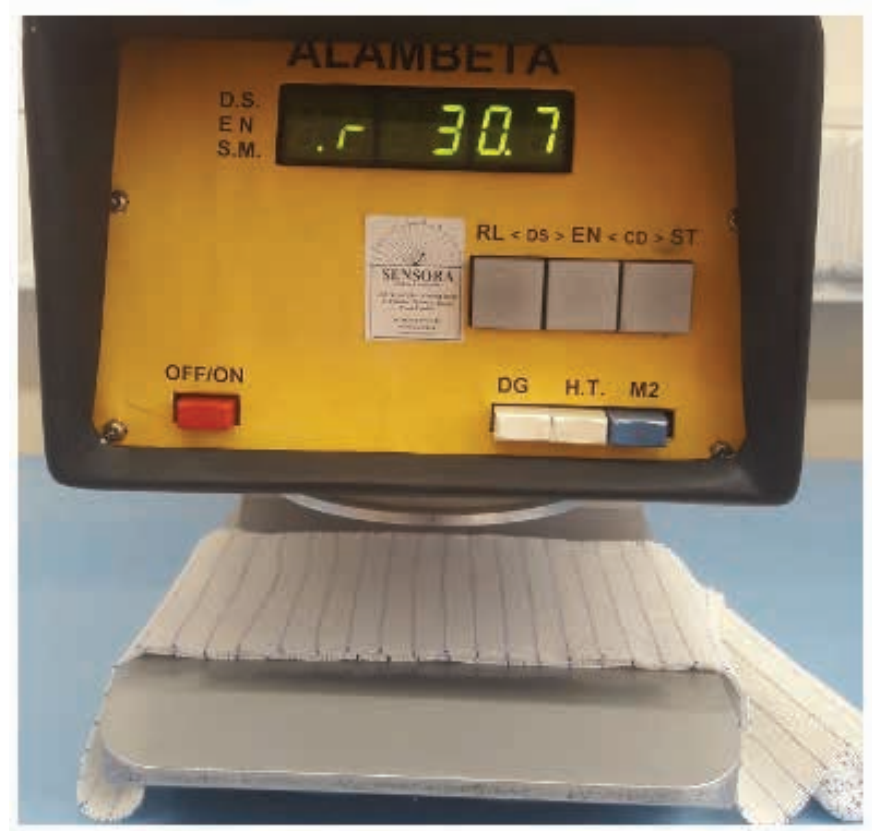

Figure 3. Thermal resistance of two bandage layers on the ALAMBETA testing device.

applied tension as a function of the total bandage thickness and fiber density, as illustrated in Figures 7 and 8.

The same analysis is proved for the three layers of bandages as demonstrated in Figures 6 and 8. Moreover, the effect of higher applied tension by three-layer bandaging appeared as the third main factor that decreases the volume of the air layers between the adjacent bandage layers.

\subsection{Validation of the experimental $R_{c t}$ results on TFM and ALAMBETA with three theoretical models}

The experimental results of $R_{c t}$ match with the three mathematical models that the increase in total fabric (WCB layers) thickness is associated with an enhancement in the $R_{c t}$ values, as displayed in Figure 9. Moreover, there are significant similarities between the ALAMBETA results and both Schuhmeister and Militky models, at approximately $92 \%$ and $93 \%$ respectively (see Figure 11); whereas the

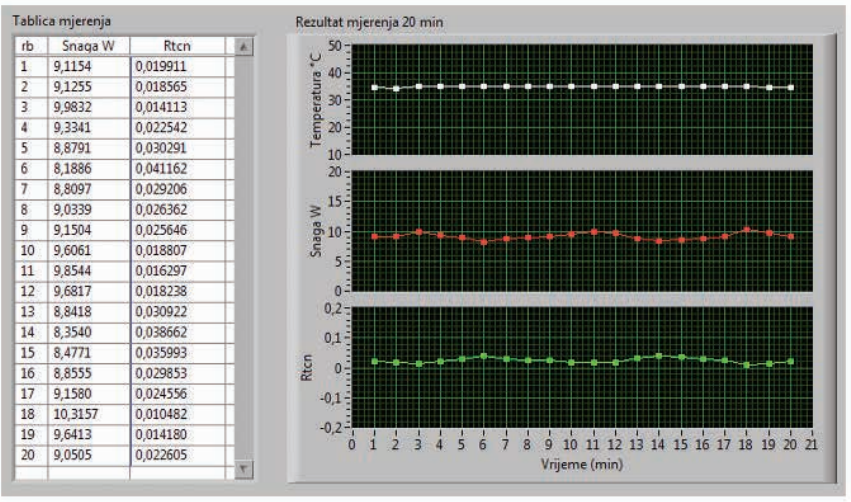

Figure 4. Measuring $R_{c t}$ while wrapping the compression bandage over socks.

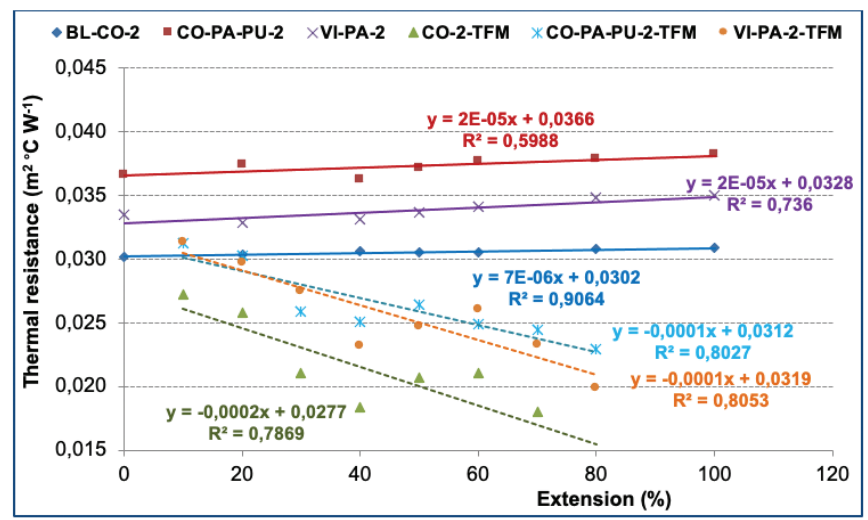

Figure 5. Effect of applied extension on thermal resistance of two layers of bandage on ALAMBETA and TFM. *Note that all the sample codes with the abbreviation TFM, such as CO-2-TFM, indicates testing results on the TFM for Figures 5-8, whereas the other codes like BLCO-2 refer to the ALAMBETA tester.

correspondence values for the TFM are approximately $82 \%$ and $83 \%$ respectively, as shown in Figure 12 . This may be because the ALAMBETA testing corresponded well to the use of socks inside a shoe (boundary conditions of first order). The ALAMBETA enables fast measurement of both steady-state and transient-state thermal properties, as shown in Figure 10. This diagram clearly demonstrated the maximum $q_{\max }$, dynamic (transient) $q_{d y n}$, and steady-state $q_{\text {steady }}$ heat flow [42].

The transient heat flow is shown in Eq. (10), whereas the steady-state heat flow is shown in Eq. (11) as follows:

$$
\begin{aligned}
& q_{d y n}=\frac{b \cdot\left(T_{1}-T_{2}\right)}{\sqrt{ } \pi \tau} \\
& q_{\text {seady }}=\frac{T_{1}-T_{2}}{R_{c t}}
\end{aligned}
$$

where $b$ is the thermal absorptivity $\left(\mathrm{W} \mathrm{s}^{0.5} / \mathrm{m}^{2} / \mathrm{K}^{1}\right),\left(\Delta T=T_{1}-T_{2}\right)$, is the temperature difference between the two convection surfaces, and $\tau$ is the tortuosity [-] [43]. The first mathematical model (ME-2) has significant deviations at approximately $15 \%$ and $25 \%$ with the recorded experimental $R_{c t}$ values on both ALAMBETA and TFM, respectively. These results confirm that the Schuhmeister and Militky models enhanced the prediction of $R_{c t}$ values for WCBs. 


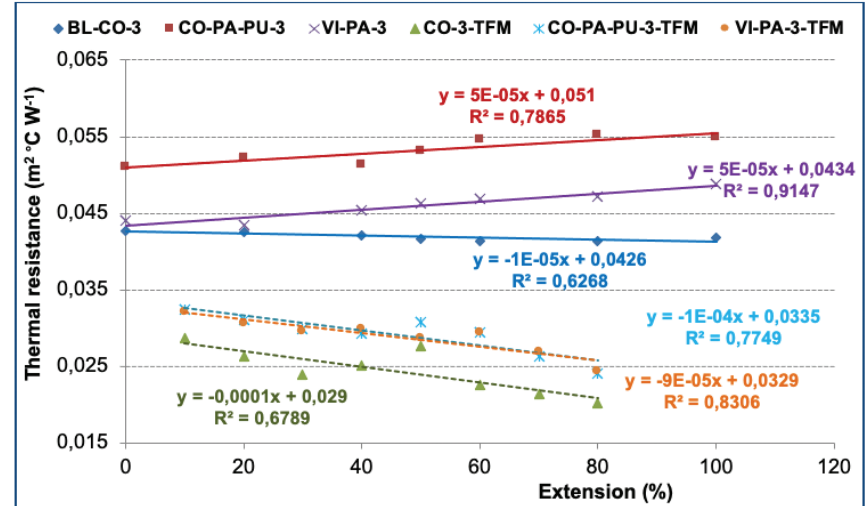

Figure 6. Effect of applied extension on thermal resistance of threelayer bandage on ALAMBETA and TFM.

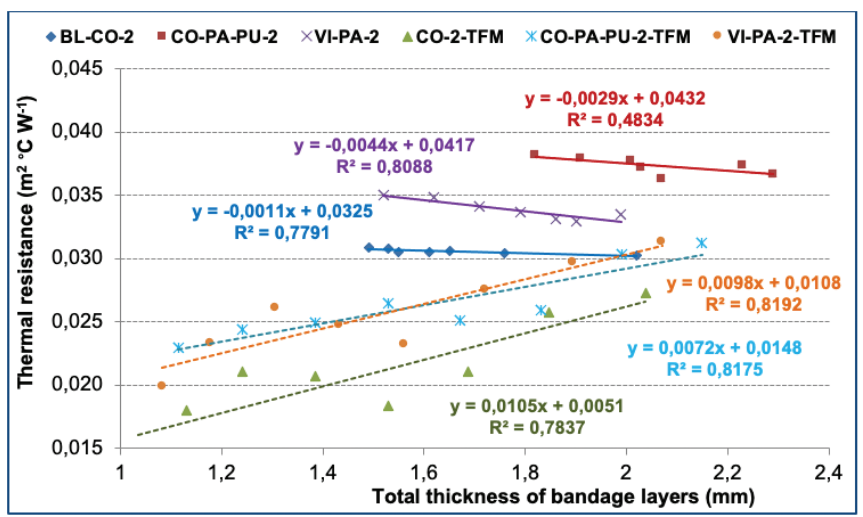

Figure 7. Effect of total bandage thickness on thermal resistance of two-layer bandage on ALAMBETA and TFM.

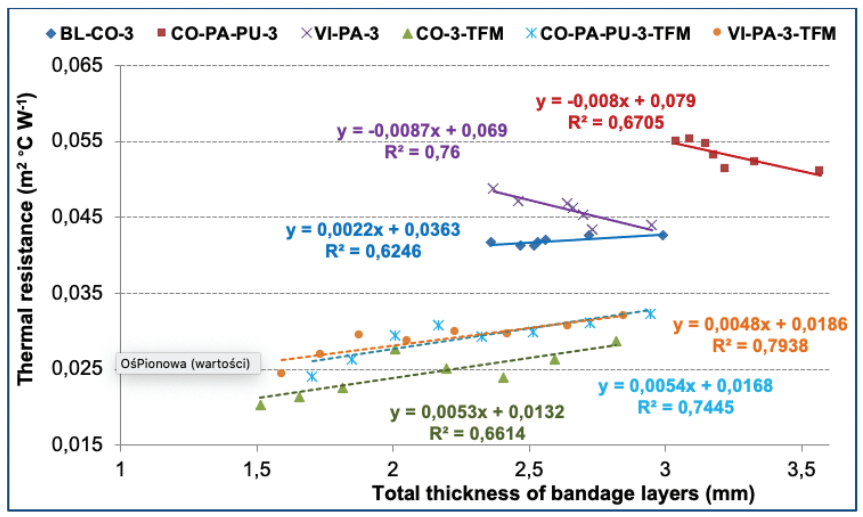

Figure 8. Effect of total bandage thickness on thermal resistance of three-layer bandage on ALAMBETA and TFM.

\section{Conclusion}

The experimental evaluation of $R_{c t}$ for the three main types of WCBs was performed on TFM and ALAMBETA testers and validated using three theoretical models. The $R_{c t}$ values improved when the bandage volumetric porosity increased as the static air existed between each two adjacent fabric layers and between fibers inside the yarn (the intra-yarn porosity). There is a strong correlation between the Schuhmeister and Militky models with the ALAMBETA results; the maximum deviation was only $8 \%$ and $7 \%$, respectively, whereas the deviations with the TFM were $18 \%$ and $17 \%$, respectively.

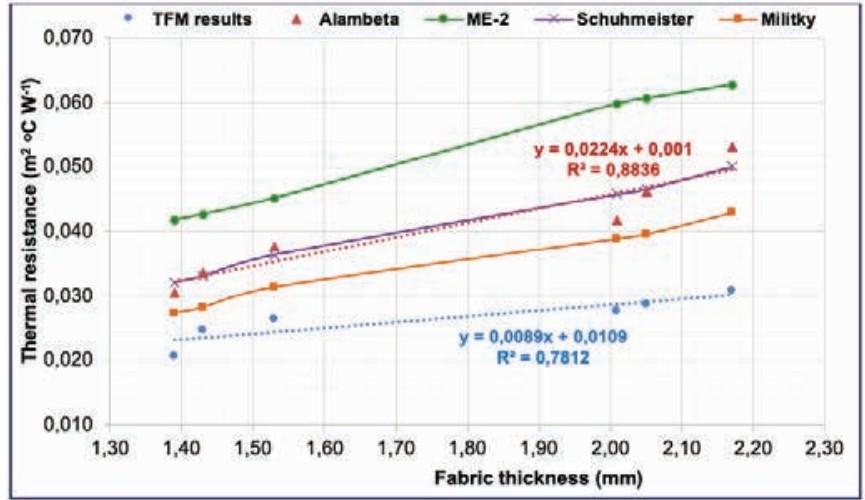

Figure 9. Experimental thermal resistance results for bandages by thermal foot manikin and ALAMBETA versus theoretical calculations by the Maxwell-Eucken2, Schuhmeister, and Militky models.

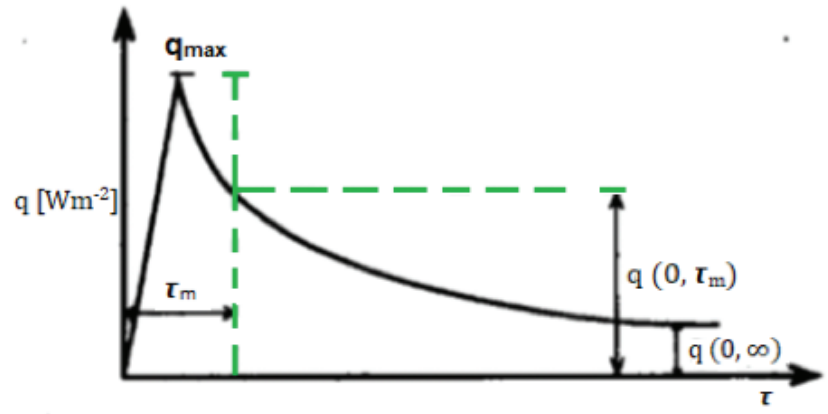

Figure 10. Time-dependence heat flow after contact [42].

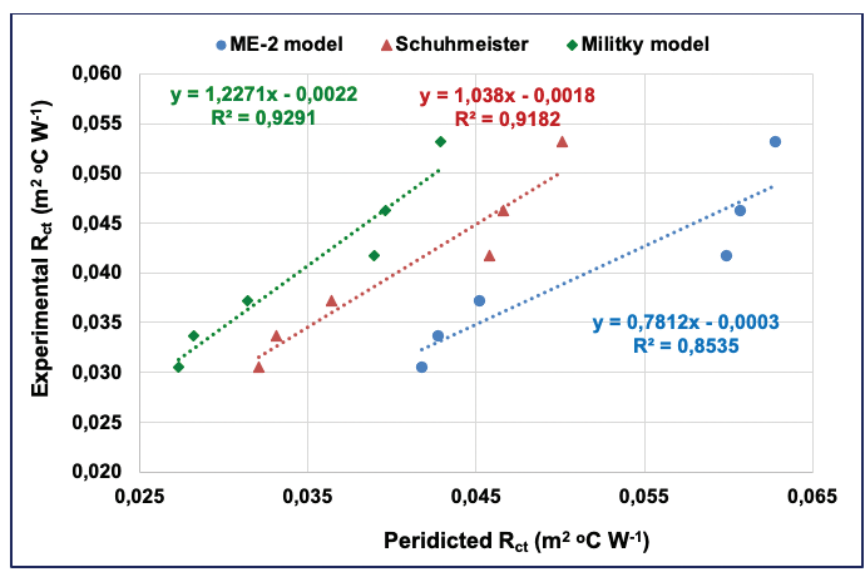

Figure 11. Experimental thermal resistance for bandages by ALAMBETA versus theoretical calculations by the Maxwell-Eucken2, Schuhmeister, and Militky models.

The obtained results of $R_{c t}$ in the case of WCB confirmed that clothed TFM is more accurate for measuring $R_{c t 0}$ and the corresponding values of $R_{c t}$ due to more stabilization and less effect of air convection. There were significant deviations in the experimental results between ALAMBETA and TFM. Hence, the TFM might be technically recommended for testing the $R_{c t}$ of WCB because the high levels of applied tension during the bandage application were more effective on the TFM results.

\section{Acknowledgments}

The authors acknowledge the cooperation of their colleagues, Dr Emilija Zdraveva and Dora Hranilović, especially for the testing of some samples. This research is supported by Student 


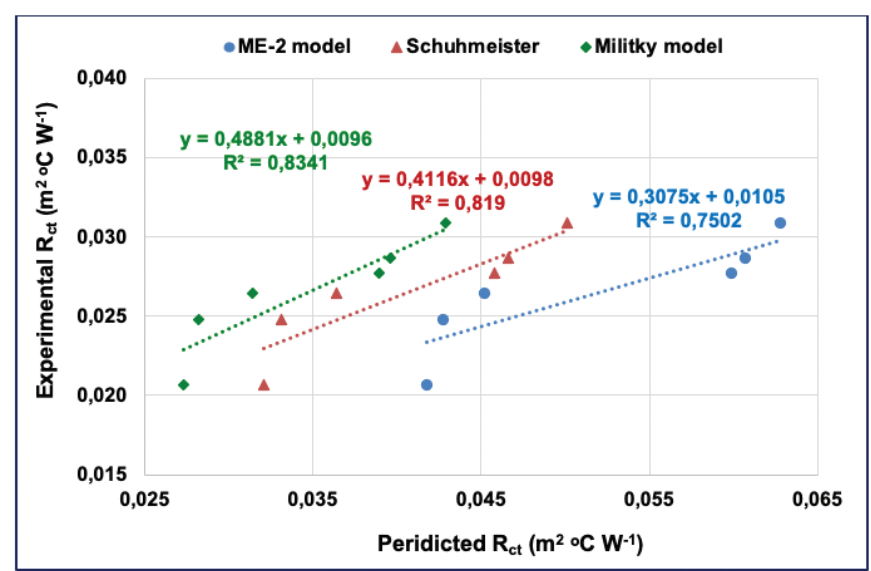

Figure 12. Experimental thermal resistance for bandages by therma foot manikin versus theoretical calculations by the Maxwell-Eucken2, Schuhmeister, and Militky models.

Grant Schemes (2020-6064, internal number SGS 21410), Faculty of Textile Engineering, Technical University of Liberec.

\section{References}

[1] Utkun, E. (2015). A research on various comfort properties of interlock knitted fabrics. Industria Textila, 66(1).

[2] Aboalasaad, A. R., Sirková, B. K., Tešinová, P., Khalil, A. (2019). Guidelines for measuring thermal resistance on thermal foot manikin. Materials Today: Proceedings.

[3] Huang, J. (2016). Review of heat and water vapor transfer through multilayer fabrics. Textile Research Journal, 86(3), 325-336.

[4] Ghosh, A., Mal, P., Majumdar, A., Banerjee, D. (2017). An investigation on air and thermal transmission through knitted fabric structures using the Taguchi method. Autex Research Journal, 17(2), 152-163.

[5] Qian, X., Fan, J. (2009). A quasi-physical model for predicting the thermal insulation and moisture vapour resistance of clothing. Applied Ergonomics, 40(4), 577590.

[6] Cubric, I. S., Skenderi, Z. (2010). Approach to the prediction of thermophysiological comfort. In: Katalinic, $B$. (Ed.). DAAAM International Scientific Book, pp. 81-88, doi: 10.2507/daaam.scibook.2010.09.

[7] Bizjak, M., Gorjanc, D. (2014). The influence of increased elasticity on resistance of cotton fabrics. XIIIth International Izmir Textile and Apparel, April, 2-5.

[8] Çolak, S. M., Özdil, N., Ekinci, M., Kaplan, Ö. (2016). Thermophysiological comfort properties of the leathers processed with different tanning agents. Tekstil ve Konfeksiyon, 26(4), 436-443.

[9] Nilsson, H., Holmér, I. (2000). Proceedings of the Third International Meeting on Thermal Manikin Testing, 3IMM, at the National Institute for Working Life, October 12-13, 1999. Web site: www.niwl.se/ah/nr2000:4

[10] Aboalasaad, A. R., Skenderi, Z., Kolčavová, S. B., Khalil, A. A. (2020). Analysis of factors affecting thermal comfort properties of woven compression bandages. Autex Research Journal, 20(2), 178-185.
[11] Aboalasaad, A. R., Sirková, B. K., Ahmad, Z. (2019). Influence of tensile stress on woven compression bandage structure and porosity. Autex Research Journal, 1(aheadof-print).

[12] Xiong, X., Venkataraman, M., Jašíková, D., Yang, T., Mishra, R., et al. (2019). An experimental evaluation of convective heat transfer in multi-layered fibrous materials composed by different middle layer structures. Journal of Industrial Textiles, doi: 10.1177/1528083719878845.

[13] Saville, B. P. (2000). Physical testing of textiles. Woodhead Publishing Ltd. and CRC Press LLC (North and South America), pp. 210-212.

[14] Dahoo, P. R., Khettab, M., Chong, C., Girard, A., Pougnet, $P$. (2015). Impact of voids in interconnection materials. In: Embedded mechatronic systems 2. Elsevier, pp. 79-106.

[15] Abdel-Rehim, Z. S., Saad, M. M., El-Shakankery, M., Hanafy, I. (2006). Textile fabrics as thermal insulators. AUTEX Research Journal, 6(3), 148-161.

[16] Khalil, A., Fouda, A., Těšinová, P., Eldeeb, A. S. (2020). Comprehensive assessment of the properties of cotton single Jersey knitted fabrics produced from different Lycra States. Autex Research Journal, 1(ahead-of-print).

[17] Bhattacharjee, D., Kothari, V. K. (2009). Heat transfer through woven textiles. International Journal of Heat and Mass Transfer, 52(7-8), 2155-2160.

[18] Jaeger, J. C., Carslaw, H. S. (1959). Conduction of heat in solids. Clarendon P.

[19] Cleland, A. C. (1990). Food refrigeration processes. Elsevier Applied Science.

[20] Cleland, A. C., Earle, R. L. (1977). A comparison of analytical and numerical methods of predicting the freezing times of foods. Journal of Food Science, 42(5), 1390-1395.

[21] Schuhmeister, J. (1877). Ber. K. Akad. Wien (Math-Naturw. Klasse), 76, 283.

[22] Baxter, S. T. (1946). The thermal conductivity of textiles. Proceedings of the Physical Society, 58(1), 105.

[23] Militky, J. (2011). Cut resistance of textile fabrics, selected topics of textile and material science. TUL FT Liberec.

[24] Bogaty, H., Hollies, N. R., Harris, M. (1957). Some thermal properties of fabrics: part I: The effect of fiber arrangement. Textile Research Journal, 27(6), 445-449.

[25] Mansoor, T., Hes, L., Bajzik, V., Noman, M. T. (2020). Novel method on thermal resistance prediction and thermophysiological comfort of socks in a wet state. Textile Research Journal, doi: 10.1177/0040517520902540.

[26] Mansoor, T., Hes, L., Bajzik, V. (2020). A new approach for thermal resistance prediction of different composition plain socks in wet state (part 2). Autex Research Journal, 1(ahead-of-print).

[27] Das, A., Alagirusamy, R., Kumar, P. (2011). Study of heat transfer through multilayer clothing assemblies: a theoretical prediction. AUTEX Research Journal, 11(2), 54-60.

[28] Wei, J., Xu, S., Liu, H., Zheng, L., Qian, Y. (2015). Simplified model for predicting fabric thermal resistance according to its microstructural parameters. Fibres \& Textiles in Eastern Europe, 23, 4(112), 57-60.

[29] Srdjak, M., Skenderi, Z., Cubric, I. S. (2009). Water vapor resistance of knitted fabrics under different environmental conditions. Fibers \& Textiles in Eastern Europe, 17(2), 7275 . 
[30] Oğlakcioğlu, N., Marmarali, A. (2007). Thermal comfort properties of some knitted structures. Fibers \& Textiles in Eastern Europe, 15(5-6), 64-65.

[31] Mangat, M. M., Hes, L., Bajzík, V. (2015). Thermal resistance models of selected fabrics in wet state and their experimental verification. Textile Research Journal, 85(2), 200-210.

[32] Mansoor, T., Hes, L., Skenderi, Z., Siddique, H. F., Hussain, S., et al. (2019). Effect of preheat setting process on heat, mass and air transfer in plain socks. The Journal of the Textile Institute, 110(2), 159-170.

[33] Hes, L., de Araujo, M. (2010). Simulation of the effect of air gaps between the skin and a wet fabric on resulting cooling flow. Textile Research Journal, 80(14), 1488-1497.

[34] Eucken, A. (1940). General laws for the thermal conductivity of various types of material and states of matter. Research in the Field of Engineering A, 11(1), 6-20.

[35] Kumar, P., Topin, F. (2014). Simultaneous determination of intrinsic solid phase conductivity and effective thermal conductivity of Kelvin like foams. Applied Thermal Engineering, 71(1), 536-547.

[36] Carson, J. K. (2017). Use of simple thermal conductivity models to assess the reliability of measured thermal conductivity data. International Journal of Refrigeration, 74, 458-464.
[37] Mao, N., Russell, S. J. (2007). The thermal insulation properties of spacer fabrics with a mechanically integrated wool fiber surface. Textile Research Journal, 77(12), 914922.

[38] Militky J. (2006). Prediction of textile fabrics thermal conductivity. In: Fan $J$ (Ed.). Thermal manikins and modelling, Hong Kong Polytechnic University, pp. 131-138.

[39] Ullmann, F. (2008). Ullmann's fibers, Vol. 1. Wiley-VCH Verlag (Weinheim).

[40] Oliveira, A. V. M., Gaspar, A. R., Francisco, S. C., Quintela, $D$. A. (2014). Analysis of natural and forced convection heat losses from a thermal manikin: Comparative assessment of the static and dynamic postures. Journal of Wind Engineering and Industrial Aerodynamics, 132, 66-76.

[41] Hes, L. (2008). Non-destructive determination of comfort parameters during marketing of functional garments and clothing. Indian Journal of Fibre and Textile Research, 33, 239-245.

[42] Hes, L., Dolezal, I. (1989). New method and equipment for measuring thermal properties of textiles. Sen'i Kikai Gakkaishi (Journal of the Textile Machinery Society of Japan), 42(8), T124-T128.

[43] Neves, S. F., Campos, J. B. L. M., Mayor, T. S. (2015). On the determination of parameters required for numerical studies of heat and mass transfer through textilesMethodologies and experimental procedures. International Journal of Heat and Mass Transfer, 81, 272-282. 